\title{
Schwannoma of Parapharyngeal Space
}

\author{
Girish Giraddi · Shrinivas S. Vanaki • \\ R. S. Puranik
}

Received: 17 October 2007/ Accepted: 15 April 2010/Published online: 22 September 2010

(C) Association of Oral and Maxillofacial Surgeons of India 2010

\begin{abstract}
The tumours of the parapharyngeal region account for only $0.5 \%$ of all the head and neck tumours. Interestingly schwanomas are much common in this region. Here a case of schwanoma of parapharyngeal space in a 24year-old female is reported with an emphasis on surgical treatment.
\end{abstract}

Keywords Schwanoma $\cdot$ Neurilemmoma $\cdot$ Parapharngeal space $\cdot$ Treatment

\section{Introduction}

Parapharyngeal Space (PPS) tumours are very rare and account for only $0.5 \%$ of all head and neck tumours [1]. Approximately $50 \%$ of the tumours have a salivary origin, $20 \%$ are neurogenic and the remaining $30 \%$ are represented by tumours such as benign and malignant lymphoreticular lesions, metastatic lesions and carotid body tumours. Schwannoma (neurilemmoma) is the most common neural tumour next to salivary gland tumour found in the PPS. Vagus nerve is reported to be the origin for $50 \%$ of parapharyngeal schwannomas and cervical sympathetic chain is the next common source.

Schwannoma is an uncommon benign neurogenic tumour arising from schwann cells or supporting fibroblast of peripheral, cranial or autonomic nerves. Up to $45 \%$ of schwannomas are seen in the head and neck region, most commonly seen in young and middle aged and are characterized by slow insidious growth [2]. The clinical

G. Giraddi · S. S. Vanaki $(\bowtie) \cdot$ R. S. Puranik

Department of Oral Pathology, PMNM Dental College

and Hospital, Bagalkot 587 101, Karnataka, India

e-mail: drssvanaki@yahoo.co.in presentation of schwannoma varies with the anatomical area involved [3].

Surgical excision has been the treatment of choice and recurrence is very rare.

\section{Case Report}

A 24-year-old female patient reported with a swelling in the throat, difficulty in swallowing since 4 months. She also complained of hoarseness of voice for a period of 4 years. Clinical examination revealed a tender and firm solitary mass of $4 \times 4 \mathrm{~cm}$ bulging into the lumen of the pharynx on the left side (Fig. 1). Overlying mucosa was normal. Swelling was palpable below the angle of mandible extra-orally of the left side. The CT scan showed a mass of $3.4 \times 3.9 \mathrm{~cm}$ in the parapharyngeal space extending up to greater cornu of hyoid bone. The mass did not involve any vital structures (Fig. 2).

Preoperative tracheotomy was performed. The lesion was approached by a mandibular swing access osteotomy. Modified midline lip split incision was connected to submandibular incision (Fig. 3). After incising the skin, platysma and deep cervical fascia the inferior border of the mandible was reached. Mandible was exposed in the symphyseal region and two $2 \mathrm{~mm}$ miniplates were adapted and holes were drilled for $8 \mathrm{~mm}$ long screws. A midline osteotomy was made using surgical saw (Fig. 4). Periosteum and lingual mucosa was separated from the mandible. The mandible was swung without separating it from buccal tissues. A reddish mass with a thick capsule was encountered (Fig. 5). With a sharp and blunt dissection it was separated from the surrounding structures. Complete excision was achieved without any complications. Preoperative CT finding that the tumour did not involve any 


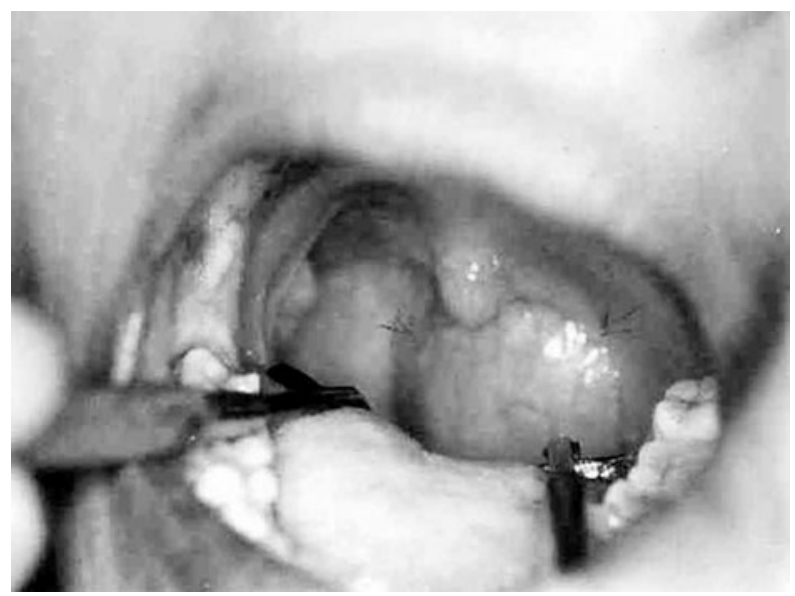

Fig. 1 Intra-oral view

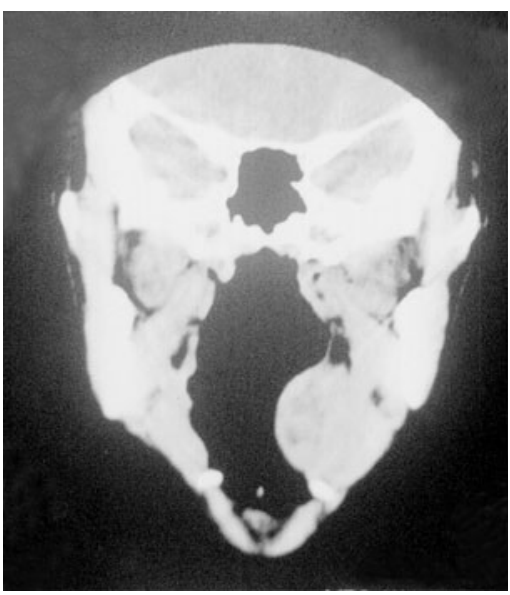

Fig. 2 Coronal CT of the lesion

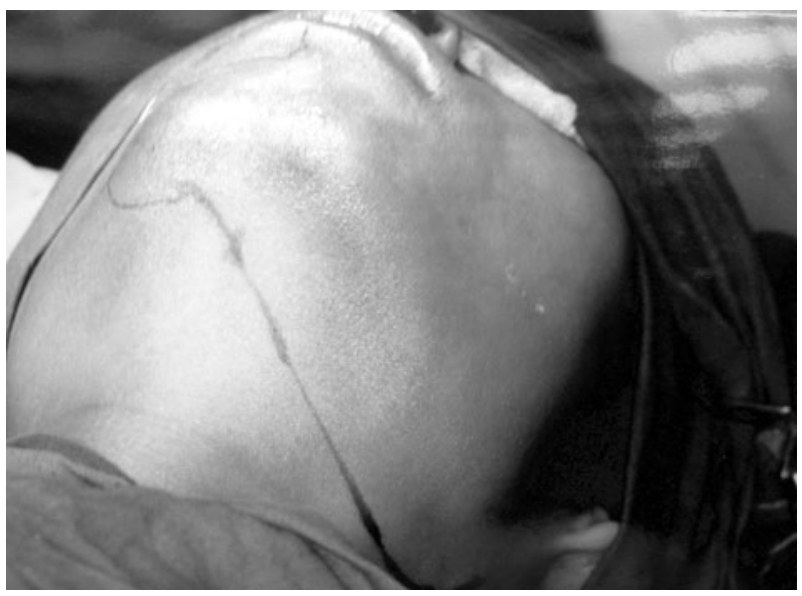

Fig. 3 Incision

nerve and surrounding structures was confirmed intraoperatively. Mandible was fixed using previously adapted miniplates (Fig. 6) and wound was closed in layers after

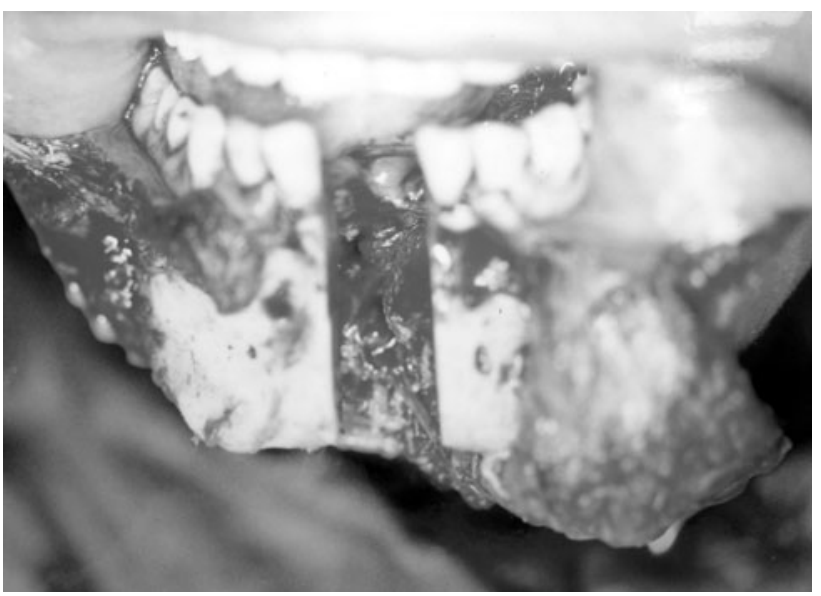

Fig. 4 Midline osteotomy

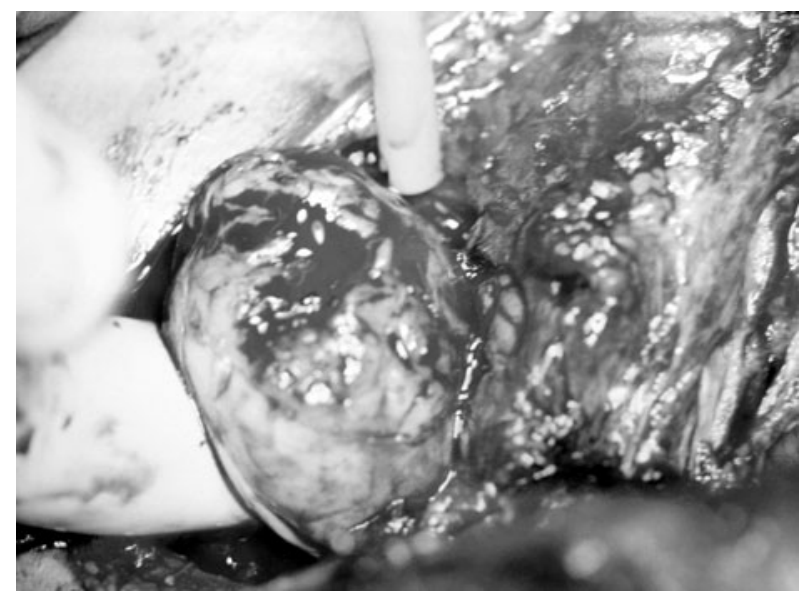

Fig. 5 Intraoperative view

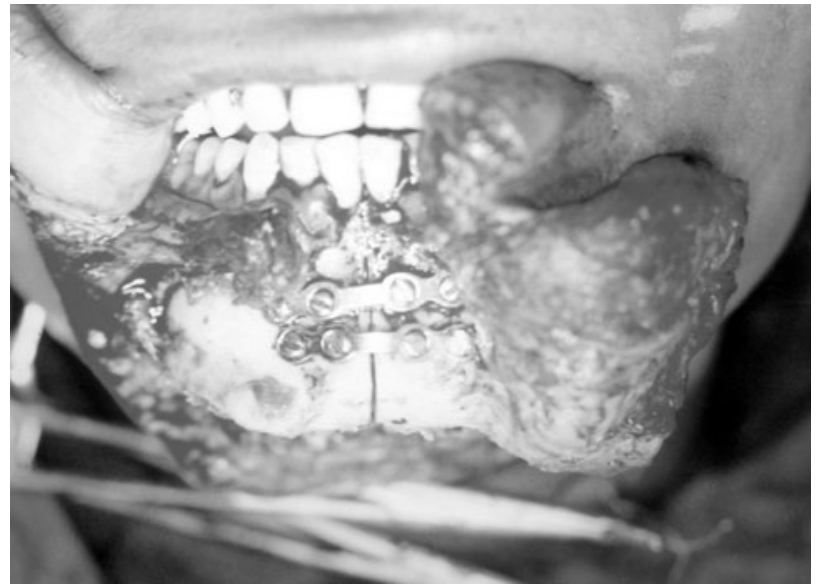

Fig. 6 Miniplate fixation

securing a suction drain. Grossly the tumour measured $3 \times$ $3 \times 3 \mathrm{~cm}$ and was well encapsulated (Fig. 7). Microscopic examination showed lesional area containing Antoni A, 


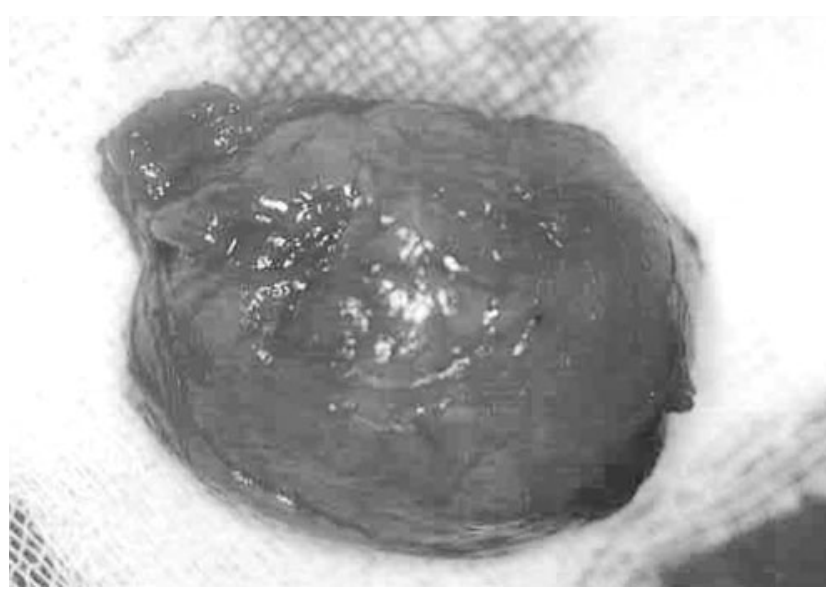

Fig. 7 Excised specimen

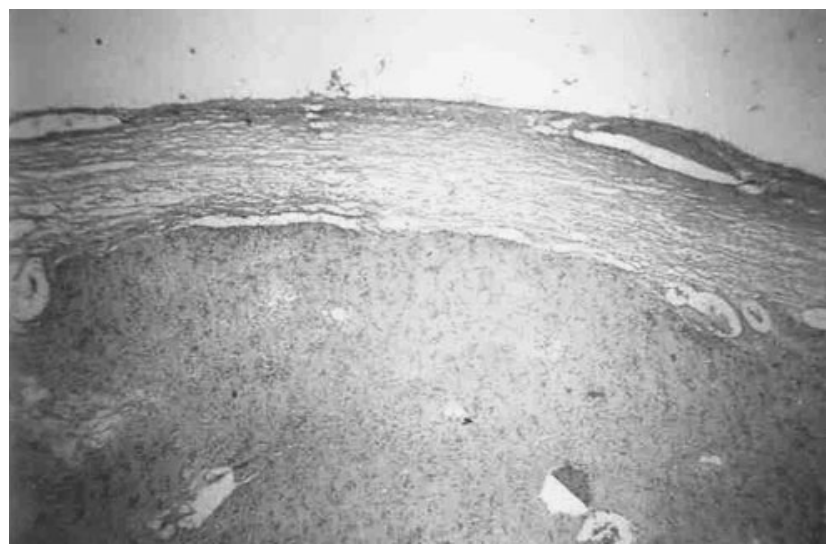

Fig. 8 Histopathological picture $(H \& E, \times 10)$

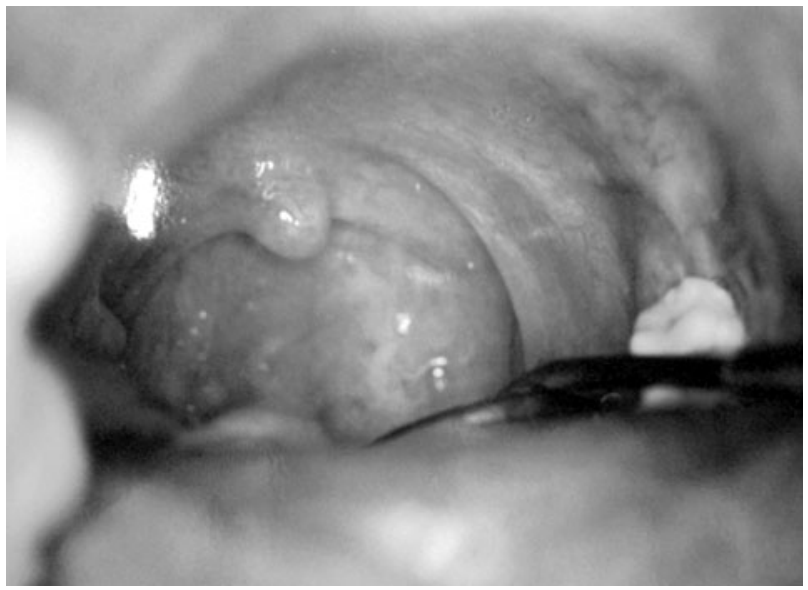

Fig. 9 Intra-oral (Postoperative)

Antoni B along with verrucay bodies, histological features consistent with schwannoma (Fig. 8).

Postoperative recovery was un-eventful and no recurrence was seen for a follow-up period of 5 years (Figs. 9, $10)$.

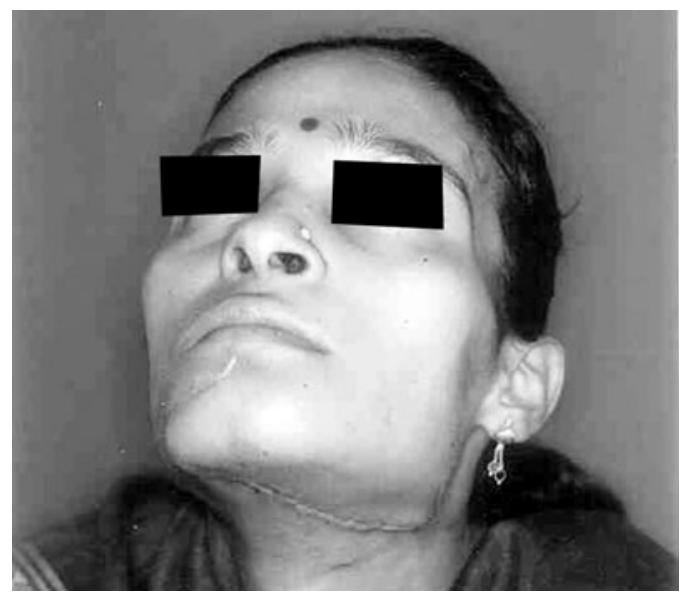

Fig. 10 Extra-oral (Postoperative)

\section{Discussion}

Schwannomas are well-known tumours to occur in the head and neck (25-48\%) region. They are reported to occur in face, scalp, intracranial cavity, orbit, nasal and oral cavities, mastoid, parapharyngeal space, larynx and medial and lateral regions of the neck $[2,3]$. This neoplasm is considered to originate from either Schwann cell or fibroblast supporting the nerve. The PPS is a potential site reported to house spectrum of tumours, most of them being benign. Schwannomas of PPS although less common however when present are usually known to arise from vagus nerve and sympathetic trunk $[3,4]$. Generally schwannomas are characterized by slow and asymptomatic growth; however, its progressive growth in parapharyngeal region may result in pressure effect manifestations like dysphasia and hoarseness of voice. Although schwannoma is most commonly seen in young and middle aged adults the parapharygeal schwannoma may be observed in patients between 30 and 70 years of age. In the present case patient was 24 years old and experienced hoarseness of voice for 4 years and difficulty in swallowing for 4 months. Microscopically they are consistently capsulated with the presence of Anthoni A and Anthoni B cells along with Verrucay bodies. Longstanding schwannomas are known to show cystic degeneration, fibrosis and hemorrhage [3].

The surgical resection has shown to be the accepted treatment of schwannomas [1, 2, 5]. Some authors suggest preoperative evaluation with imaging modalities like CT and MRI in determining the nerve of origin may reduce the postoperative neural deficits $[2,6]$. Transoral biopsy and excision of PPS schwannomas is reported to be associated with complications like incomplete removal, haemorrhage, infection and cranial nerve damage. The trans-cervical, transparotid, transzygomatic, transmandibular, and combination of transparotid and transcervical surgical approaches are currently preferred techniques. The preoperative CT 
evaluation and mandibular swing access osteotomy (transmandibular) was employed in the present case successfully in removing the tumour without any complication.

\section{Conclusion}

Parapharyngeal schwannomas are rare benign neoplasms. They are usually detected late after considerable signs and symptoms appear. Preoperative transoral biopsy is contraindicated as there is risk of tumour rupture and hemorrhage and the procedure can cause adherence of mucosa to tumour making later removal difficult. Careful preoperative CT or MRI image evaluation and total surgical excision is the treatment of choice. Recurrence is rare after complete excision.

\section{References}

1. Batsakis JG, Sneige N (1986) Parapharyngeal and retropharyngeal space diseases. Ann Otol Rhinol Laryngol 21:173

2. Neville BW, Damm DD, Allen CM, Bouqot JE (2002) Oral and maxillofacial pathology, 2nd edn. W. B. Saunders, Philadelphia, pp 456-457

3. Sharaki MM, Talaat M, Hamam SM (1982) Schwannoma of head and neck. Clin Otolaryngol Allied Sci 7(4):245-251

4. Thawley SE, Panje WR, Batsaki JG, Lindberg RD (1987) Comprehensive management of head and neck tumour, vol I, 2nd edn. Saunders, Philadelphia, pp 752-754

5. Khafif A, Segev Y, Kaplan DM, Gil Z, Fliss DM (2005) Surgical management of parapharyngeal space tumours: 10 years review. Otolaryngol Head Neck Surg 132(3):401-406

6. Saito DM, Glastonbury CM, El-Sayed IH, Eisele DW (2007) Parapharyngeal space Schwannomas-preoperative imaging determination of nerve of origin. Arch Otolaryngol Head Neck Surg 133(7):662-667 